\title{
A PÓS-GRADUAÇÃO DE PROFESSORES DA EDUCAÇÃO BÁSICA: UMA REVISÃO DE LITERATURA
}

Maria Regina Viveiros de Carvalho ${ }^{\mathrm{I}}$

http://dx.doi.org/10.24109/9786581041076.ceppe.v2a4

\section{RESUMO}

Discute um dos objetivos da Meta 16 do Plano Nacional de Educação (PNE), que diz respeito à formação em nível de pós-graduação dos professores da educação básica, analisa os argumentos que embasam as políticas sobre o assunto, investiga os eventuais resultados dessas políticas e verifica se essa formação é traduzida em melhores resultados educacionais. Selecionou-se um conjunto de 63 estudos sobre o tema, que foram organizados e classificados segundo o tipo e a natureza de pesquisa, os indicadores e os resultados obtidos. Os estudos qualitativos apresentaram resultados positivos para as políticas de pós-graduação de professores e, na grande maioria, não encontraram efeitos importantes, com algumas exceções para formação em ciências e matemática. Recomenda-se o desenvolvimento de pesquisas que avaliem com maior sensibilidade as implicações e o valor agregado pela formação pós-graduada do professor da educação básica.

Palavras-chave: curso de pós-graduação; educação básica; formação do professor.

\footnotetext{
Maria Regina Viveiros de Carvalho é mestre em Administração Pública pela Universidade de Brasília (UnB), pesquisadora no Instituto Nacional de Estudos e Pesquisas Educacionais Anísio Teixeira, com atuação na Diretoria de Estudos Educacionais (Dired).E-mail: mreginavcarvalho@gmail.com
} 


\section{INTRODUÇÃO}

No cenário desafiador atual - aumento na demanda por professores para a universalização da educação básica, a necessidade de que sejam bem qualificados para a melhoria da qualidade da educação e que estejam em constante aperfeiçoamento para fazer frente às mudanças tecnológicas e socioculturais recentes -, o trabalho do professor está imerso em um contexto complexo de dimensões que demandam, além da bagagem necessária de conhecimentos, um conjunto de habilidades e posturas profissionais que impactam diretamente o processo pedagógico.

Faria, Reis e Peralta (2017a) afirmam que, para o exercício da profissão, é imperativo investir na formação e na atualização de conhecimentos, técnicas e competências do professor, ao atuar em um contexto que, segundo Leite (2005, p. 371), reclama que a formação "se amplie para além da formação inicial e a campos para além das fronteiras dos conhecimentos disciplinares a que cada um/a se encontra vinculado/a, sem, no entanto, os deixar de ter em conta”. Portella (2008), por sua vez, afirma que os profissionais que se mantêm estagnados e com formação deficiente têm mais dificuldade nesse contexto.

Desse modo, tendo em vista a importância do professor para o sucesso do aprendizado dos alunos (Mello, 2000; Angelucci et al., 2004; Moriconi, 2012; Bauer; Sousa, 2015), considerações sobre a sua formação estão no centro das políticas educacionais. Assim prevê o PNE (Brasil, 2014), ao instituir quatro de suas metas referentes ao professor. Discute-se, neste artigo, especificamente, a Meta 16, que diz respeito à formação em nível de pós-graduação e à formação continuada dos professores da educação básica, estabelecendo como objetivo

[...] formar, em nível de pós-graduação, 50\% dos professores da Educação Básica, até o último ano de vigência deste PNE, e garantir a todos os(as) profissionais da Educação Básica formação continuada em sua área de atuação, considerando as necessidades, demandas e contextualizações dos sistemas de ensino (Brasil, 2014).

O Plano Nacional de Pós-Graduação (PNPG) 2011-2020 (Brasil. Capes, 2010) destaca, entre as ações relacionadas à educação básica, a necessidade de se dar atenção à questão da qualificação dos professores para o exercício da profissão, salientando que pesquisas precisam ser desenvolvidas no âmbito dos programas de pós-graduação para estudar o perfil dos professores, sua qualificação e seus interesses quanto às tarefas exigidas pelas escolas, e desenvolver estudos sobre a baixa aprendizagem dos alunos e sobre a ampliação das atribuições da escola, que, atualmente, precisa "atender os casos de violência familiar, abusos sexuais, exploração do trabalho infantil, falta de cuidados com a saúde” (Brasil. Capes, 2010, p. 173), além do uso de drogas e da violência na vizinhança - problemas que afetam a aprendizagem e precisam ser tratados pela escola. 
Em diagnóstico realizado pelo MEC em 2011, como fundamentação para as discussões do PNE no Congresso, a importância da pós-graduação de professores é justificada da seguinte forma:

[...] além da formação em nível superior na área de atuação, é desejável que os professores aprofundem seus conhecimentos por meio de cursos de pós-graduação. Ao passar por esses cursos, sejam eles stricto sensu ou lato sensu, os professores são expostos a metodologias científicas, aprofundam seus conhecimentos, ampliam seu olhar com relação à sala de aula e, consequentemente, têm maior propensão a estimular o raciocínio científico em seus alunos (Brasil. MEC, 2011, p. 93).

De forma geral, as políticas públicas para docentes encorajam a evolução do percurso formativo do professor, quando, por exemplo, incluem na remuneração deste um adicional por nível de titulação obtido. No entanto, a despeito do tamanho dos investimentos necessários para a formação pós-graduada do professor, os efeitos dessas políticas sobre a qualidade da educação têm sido pouco estudados na literatura, e os resultados obtidos são, às vezes, conflitantes.

Estudos analisados por Horn e Jang (2017) mostram que a relação entre o nível de titulação do professor e seus efeitos sobre os resultados dos alunos é complexa e ainda não foi estudada a contento. Alguns dos estudos analisados pelos autores mostram que pode existir alguma relação, a depender de a área de titulação do professor ser congruente com a disciplina e a etapa de ensino, mas a maioria das pesquisas encontrou resultados indefinidos. Concordando com esses achados, Hill (2007) afirma que, na maioria dos casos, os resultados demonstraram não existir relação entre possuir um título de mestre e um melhor desempenho dos estudantes. A exceção foram estudos que mostraram existir relação positiva do mestrado do professor em matemática para os que lecionam a disciplina no ensino médio.

Darling-Hammond, Berry e Thoreson (2001) fazem uma revisão do estudo de Goldhaber e Brewer (2000), os quais concluíram que a formação do professor não tem efeito sobre o resultado dos alunos, e que o Estado deveria eliminar o requisito de formação para o licenciamento de professores. Darling-Hammond, Berry e Thoreson (2001) discordam, no entanto, ponderando que as conclusões resultaram de generalizações baseadas em evidências tênues. Embora os autores reconheçam que pesquisas adicionais precisam ser desenvolvidas para elucidar o modo como a formação do professor opera para o sucesso do ensino, entendem que o processo de formação reflete uma preparação que adiciona valor à competência de ensino do professor ${ }^{1}$ e citam vários autores que encontraram relação positiva entre o nível

\footnotetext{
1 O conceito de formação do professor utilizado pelos autores nesse contexto diz respeito à formação no conteúdo específico da disciplina que o professor desenvolveu. Envolve variáveis que contemplam o nível de bacharelado ou mestrado na área, com certificação correspondente para lecionar a
} 
de formação do professor, sua capacidade de compreensão e percepção das necessidades dos alunos, as habilidades pedagógicas que demonstram e os resultados positivos dos alunos.

Esta pesquisa tem por objetivo, especificamente, estudar a pós-graduação dos professores da educação básica, analisar os argumentos que embasam as políticas sobre o assunto e investigar os eventuais resultados dessas políticas, com base nas evidências obtidas em pesquisas científicas. Parte-se da hipótese de que o exercício da profissão de professor da educação básica exige formação de qualidade e atualização constante, para que o professor consiga lidar com os complexos desafios da educação nos dias atuais, e que a pós-graduação desses professores contribui para essa formação.

O artigo está organizado com as seguintes seções, além desta introdução: na seção 1, é realizada uma contextualização do assunto "pós-graduação de professores"; na seção 2, são descritos os procedimentos metodológicos utilizados no levantamento dos estudos analisados; na seção 3, é apresentada uma síntese dos resultados dos estudos selecionados e analisados; na seção 4, alguns desses resultados são discutidos; na última seção, são apresentadas as considerações finais.

\section{PÓS-GRADUAÇÃO DE PROFESSORES}

A Capes traz a seguinte definição sobre o que é a pós-graduação:

[...] a pós-graduação é um sistema de cursos constituído para favorecer a pesquisa científica e o treinamento avançado. Seu objetivo imediato é proporcionar ao estudante aprofundamento do saber que lhe permita alcançar elevado padrão de competência científica ou técnico-profissional, impossível de se adquirir no âmbito da graduação (Brasil. Capes, 2017).

Cury (2005) cita o parecer CFE n ${ }^{\circ}$ 977/65 (publicado no Diário Oficial da União em 20/1/1966) como sendo, ainda hoje, a grande referência doutrinária sobre a pós-graduação no Brasil. Segundo o parecer, a necessidade da pós-graduação procede do fato de que, em função do "acúmulo de conhecimentos em cada ramo das ciências e da crescente especialização das técnicas, o estudante moderno somente poderá obter, ao nível da graduação, os conhecimentos básicos de sua ciência e de sua profissão" (Definição... 1966, p. 2).

disciplina. O processo de certificação combina aspectos como o conhecimento do conteúdo da disciplina e o conhecimento da pedagogia dessa disciplina e envolve diferentes tipos/estágios (padrão, temporário, emergencial, por exemplo), que variam também conforme o estado americano em que o professor se certifica. A conclusão a que Darling-Hammond, Berry e Thoreson (2001, p. 67) chegam é que "professores com certificação mais completa produzem desempenho melhor nos seus estudantes, e que os esforços dos professores para se tornarem melhor preparados estão associados com melhores resultados de seus estudantes". 
De modo geral, acredita-se que a formação em nível de pós-graduação traga ao professor um repertório mais aprofundado de conhecimentos, competências e habilidades, enriquecendo-o como profissional. De modo específico, essa formação traz a ele especialização em uma determinada área de conhecimento, que o ajudará a enfrentar situações especiais encontradas em sua docência. Vieira (2009) destaca, ainda, como produto da formação pós-graduada, o potencial de emancipação e autonomia do professor, no que diz respeito à sua participação crítica e autodeterminada no ambiente de ensino.

A pós-graduação introduz, também, a formação do docente no campo da pesquisa acadêmica, estimulando o pensamento científico e o maior contato com pesquisadores da área, e desenvolve nesses profissionais habilidades para refletir criticamente sobre as práticas correntes, concebendo estratégias que orientem políticas para a melhoria da qualidade do ensino - como, por exemplo, adotar a iniciação à pesquisa como princípio metodológico de ensino para seus alunos ou incorporar estratégias didáticas diferentes e inovadoras à maneira de aprender e ensinar (Raush, 2012; Dixon; Ward, 2015).

Lüdke e Cruz (2005) destacam o aspecto criativo e crítico que a pesquisa pode trazer ao professor, induzindo-o ao questionamento e ao encontro de soluções para os problemas que enfrenta. Balbachevsky (2005), da mesma forma, salienta o perfil polivalente que a pós-graduação pode desenvolver no professor, além de fomentar o vínculo entre a pesquisa acadêmica e o mundo prático da docência. Ens (2006, p. 14) argumenta que

[...] algumas das maneiras de se articular ensino e pesquisa [...] possibilitam, ao futuro educador, construir e transformar a sua prática pedagógica, tanto nos anos iniciais de profissionalização docente como durante sua vida profissional e no processo de formação continuada.

No entanto, apesar da importância do contato do professor com a pesquisa na universidade, é preciso cuidar para que não haja excessivo foco na formação de pesquisadores estritamente acadêmicos, em detrimento da aproximação dessa pesquisa às questões relacionadas ao cotidiano da escola básica.

A proximidade com o "chão da escola", segundo Ramos (2015), é essencial para que haja melhoria na qualidade do ensino com a formação pós-graduada do professor, no que concorda Soares (2014, p. 443), ao afirmar "a importância de que os projetos de pós-graduação em educação sejam desenvolvidos a partir do diálogo com os cursos de formação de professores e com a realidade das escolas brasileiras de Educação Básica”, assim como Lüdke, Rodrigues e Portella (2012, p. 71), ao destacarem a "necessidade de aproximação entre as escolas da educação básica e a Universidade, se quisermos desenvolver uma pesquisa que responda aos problemas mais urgentes da nossa educação". 
Rausch (2012) refere como um dos objetivos da pós-graduação a formação de professores-pesquisadores que incorporem a pesquisa como atividade importante em sua prática cotidiana, integrada ao ensino. Segundo a autora, entretanto, na prática, os professores relatam dificuldades para desenvolverem atividades de pesquisa por falta de estrutura, de tempo e de apoio da gestão; por vezes, ainda, não entendem a pesquisa de forma sistematizada, "no sentido de se fazer ciência relacionada à docência" (Raush, 2012, p. 702). A autora assinala também um "distanciamento entre a pesquisa realizada na academia e aquela aplicada pelos professores nas escolas de educação básica” (Raush, 2012, p. 703).

Zeichner (1998) chama a atenção para esse revés, no que diz respeito ao trabalho do professor-pesquisador no contexto da escola. Segundo o autor, no meio acadêmico, tais pesquisas são consideradas triviais, pouco fundamentadas em teoria e irrelevantes para o trabalho acadêmico, e afirma que "é muito raro, por exemplo, ver citações do conhecimento produzido por professores nos artigos de pesquisadores acadêmicos ou ver o uso de conhecimento gerado por professores em programas de formação de professores", e que "é também raro ver esses professores sendo solicitados a dar palestras em congressos sobre pesquisa educacional” (Zeichner, 1998, p. 1). O autor ressalta as dificuldades também por parte dos professores escolares em relação à pesquisa acadêmica, afirmando que "muitos professores sentem que a pesquisa educacional conduzida pelos acadêmicos é irrelevante para suas vidas nas escolas; a maior parte dos professores não procura a pesquisa educacional para instruir e melhorar suas práticas” (Zeichner, 1998, p. 1).

Em sua pesquisa, Portella (2008, p. 304) destaca: “faz-se necessário ultrapassar a dicotomia entre modelos acadêmicos de formação (centrados na universidade) e práticos (centrados na escola), adotando modelos que, ao contrário, integrem essas instâncias formativas", e conclui pelo equilíbrio entre esses dois enfoques, afirmando que a formação do professor como pesquisador favorece a visão mais problematizadora e menos incauta da realidade e contribui para o desenvolvimento de capacidades e habilidades importantes para sua docência.

É preciso considerar, ainda, que a titulação pós-graduada pode resultar no afastamento do professor do ensino na educação básica. Balbachevsky (2005, p. 284) registra que alguns professores pós-graduados são absorvidos pelo ensino superior, "em universidades que oferec[em] as melhores condições e infraestruturas de pesquisa”, deixando, portanto, as redes de ensino, ou, quando permanecem nas redes, passam a ocupar cargos de direção ou coordenação (Rausch, 2012).

A esse respeito, Ramos (2015, p. 100) afirma que

[...] é necessário que os governos tenham planos de carreira capazes de manter motivado esse professor pós-graduando na sala de aula. Muitas vezes a ausência do plano de carreira, associada à formação continuada, faz com que esses professores, após a conclusão de seu curso de pós-graduação, de fato deixem de lecionar. 
Outro ponto a discutir é a assimetria que existe, em termos de distribuição de cursos de pós-graduação entre as regiões brasileiras, em função da heterogeneidade da realidade do País: mais da metade dos cursos estão concentrados na região Sudeste, com evidentes desigualdades entre regiões e instituições, como mostraram Santos e Azevedo (2009). Segundo os autores, "são as análises a respeito dos investimentos financeiros que desnudam as diferenças regionais, colocando desafios que não podem ser enfrentados apenas por políticas governamentais especificamente voltadas para a pós-graduação" (Santos; Azevedo, 2009, p. 540). Ramos (2015) acredita que, mais do que financiamento, são as questões logísticas de oferta de cursos os principais obstáculos - disponibilidade dos cursos para as regiões mais distantes dos centros formadores, principalmente em localizações rurais, no Nordeste e no Norte do país -, e defende que é preciso considerar estratégias diferentes conforme as regiões geográficas, dadas as suas especificidades.

Outra perspectiva importante ao se analisar as políticas de formação pós-graduada de professores diz respeito ao custo-benefício envolvido. É preciso levar em consideração que a exigência de pós-graduação para 50\% dos professores da educação básica acarreta custos para o Estado, em termos de oferta de programas (nas áreas de conhecimento necessárias, nas localidades necessárias, nos horários convenientes) e de custos financeiros propriamente ditos - com bolsas de estudo e licenças para os professores, por exemplo (Knapp et al., 1990). Esses custos precisam ser avaliados em relação aos benefícios que podem trazer à qualidade da educação. É sobre esse aspecto - a busca de evidências sobre efeitos ou impactos desse tipo de titulação nos resultados educacionais - que vem se concentrando grande parte dos estudos acadêmicos nas últimas décadas, e que serão parte da análise desta pesquisa.

\section{PROCEDIMENTOS DE PESQUISA}

Para analisar o que foi publicado sobre o tema da pós-graduação de professores da educação básica, realizou-se uma revisão sistemática de literatura, em que se buscou, em diretórios e em bases digitais acadêmicas (Scielo, Spell, Google Acadêmico), publicações nacionais e internacionais nos campos de ciências sociais, economia, educação e administração pública. O objetivo foi identificar informações sobre a pós-graduação de professores da educação básica disponíveis nos estudos e pesquisas, inclusive evidências sobre os efeitos dos programas.

Para a seleção inicial, foram definidas as seguintes palavras-chave (e suas versões em inglês) e as combinações entre elas: "formação do professor", "pós-graduação", "mestrado", "doutorado", "qualidade da educação", "desempenho do aluno", "efeito do professor" e adotados os seguintes critérios de seleção: i) formatos: artigos em revistas 
e periódicos, relatórios de pesquisas, teses e dissertações; ii) nas línguas portuguesa ou inglesa; iii) que fizessem referência explícita à pós-graduação de professores da educação básica.

Em seguida, escolheu-se o processo de amostragem "bola de neve", que seleciona artigos de autores referenciados por outros autores de interesse na área do estudo, com o objetivo de focar a seleção sobre o tema estudado. Buscou-se, adicionalmente, focar a pesquisa em estudos na língua portuguesa que fizessem referência conjunta à "pós-graduação" e à "educação básica”, uma vez que foram poucos os trabalhos inicialmente encontrados sobre o tema em âmbito nacional.

Os trabalhos foram, então, ordenados em função da pertinência de seus resumos (aderência ao tema). Foram selecionados 63 estudos (vide Anexo A), organizados em planilha e classificados segundo características como: i) pesquisa teórica ou empírica? ii) de natureza qualitativa ou quantitativa? iii) método/procedimento de pesquisa; iv) trata explicitamente de pós-graduação (e de que outras características)? v) identifica efeitos? vi) qual o indicador de resultado da pesquisa?

\section{RESULTADOS}

Dos 63 estudos selecionados, 27 são nacionais (43\%) e 36 estrangeiros (57\%); 11 são estudos teóricos (17\%) e 52 empíricos (83\%) - destes, 29 de abordagem quantitativa (56\%), 12 de abordagem qualitativa (23\%), 2 de abordagem mista (Gráfico 1) e 9 metaanálises (17\%).

Estudos Selecionados - método de pesquisa

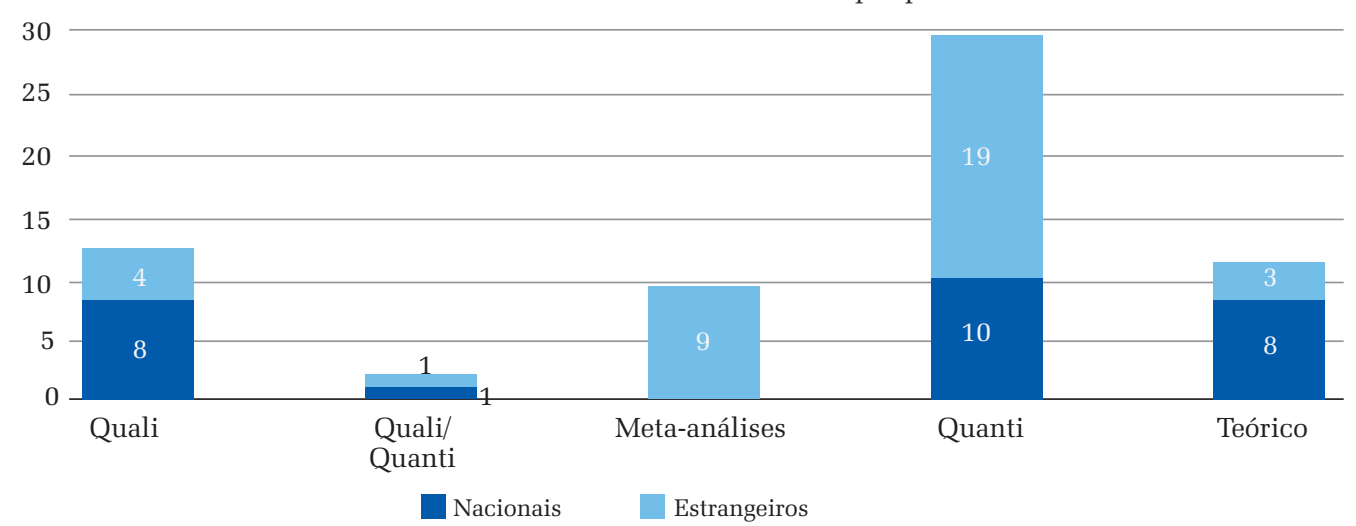

\section{GRÁFICO 1 \\ DESCRIÇÃO DOS ARTIGOS SELECIONADOS SEGUNDO O MÉTODO DE PESQUISA}

Fonte: Elaboração própria. 
Os 11 estudos teóricos apresentam discussões sobre a pós-graduação de professores da educação básica envolvendo aspectos como os listados no Gráfico 2. Em geral, esses estudos abordam a educação e o ofício do professor como objetos de pesquisas da pós-graduação, e não diretamente analisam as políticas de pós-graduação para os professores da educação básica como objeto de estudos.

Alguns problemas discutidos nos estudos são: i) o descompasso entre o conteúdo estudado na formação pós-graduada e os problemas que os professores encontram no seu dia a dia, ou seja, a distância que existe entre as pesquisas realizadas na academia e os assuntos cotidianos da escola; ii) a pouca consideração que recebem no meio acadêmico as pesquisas realizadas pelos professores da educação básica; iii) a possibilidade de que os professores pós-graduados migrem para fora da sala de aula; iv) a assimetria de distribuição de cursos de pós-graduação entre as regiões brasileiras; v) a análise dos custos em relação aos benefícios desse tipo de investimentos. Nacarato (2016), a esse respeito, aponta a necessidade de que sejam induzidas novas pesquisas para avaliar se a pós-graduação é, de fato, o melhor caminho para a formação do professor da educação básica e para avaliar o impacto desses programas sobre a eficácia dos professores.

\section{Estudos Teóricos}

Discussões sobre o valor da pesquisa em educação, para o professor e para o contexto das escolas

Discussões a respeito do estabelecimento de estratégias e diretrizes para pós-graduação de professores da educação

Descrição histórica dos planos de pós-graduação e do contexto atual

Esclarecimentos relativos a programas específicos de mestrado para professores

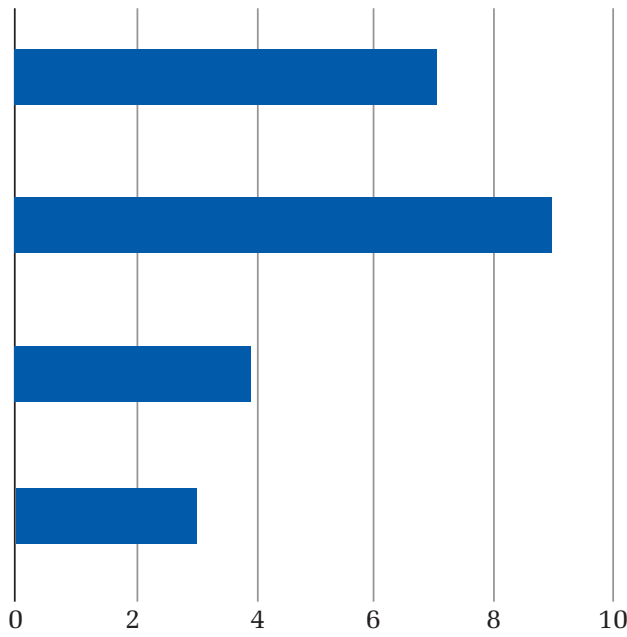

GRÁFICO 2 ASSUNTOS ABORDADOS NOS ESTUDOS TEÓRICOS

Fonte: Elaboração própria.

Dos estudos empíricos, 12 possuem enfoque qualitativo. O Gráfico 3 sintetiza os principais assuntos abordados nas pesquisas: 
Estudos Qualitativos

Investigação da opinião dos professores a

Estudos de caso envolvendo programas específicos, ou contextos escolares específicos

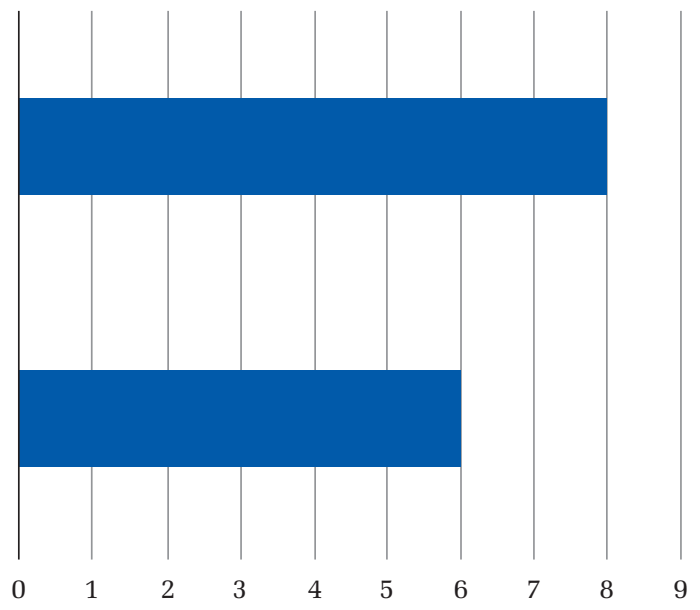

GRÁFICO 3

\section{ASSUNTOS ABORDADOS NOS ESTUDOS QUALITATIVOS}

Fonte: Elaboração própria.

Alguns estudos qualitativos empregam como método de levantamento de dados a aplicação de questionários e entrevistas a um conjunto de professores da educação básica, e mostram a prevalência da percepção de efeitos positivos da pós-graduação para esses professores. A maioria desses estudos foi conduzida por pesquisadores brasileiros ou portugueses (Araújo; Amaral, 2006; Faria; Reis; Peralta, 2017a, 2017b; Milheiro, 2017; Dixon; Ward, 2015; Lüdke; Rodrigues; Portella, 2012; Rausch, 2012; Portella, 2008), que analisaram os efeitos dessa formação do ponto de vista do profissional (autoimpacto), da sala de aula (microimpacto), das escolas (mesoimpacto) e de práticas investigativas e educativas (macroimpacto).

Apesar de buscarem a existência de efeitos positivos da formação pós-graduada dos professores, os estudos deixam claro que não foi parte do escopo identificar impactos causais diretos na aprendizagem dos alunos. Faria, Reis e Peralta (2017a, p. 1201), por exemplo, concluem que "não podemos afirmar que aqueles que são ensinados por docentes com formação pós-graduada têm melhores resultados, mas sim que estes alunos têm ao seu dispor mais ferramentas que os podem conduzir ao sucesso".

O Quadro 1 apresenta um resumo dos efeitos identificados por esse grupo de estudos: 


\section{QUADRO 1}

\section{EFEITOS DA PÓS-GRADUAÇÃO DE PROFESSORES DA EDUCAÇÃO BÁSICA}

\section{Impacto pessoal (autoimpacto)}

- atualização e aquisição de novos conhecimentos, com maior domínio, profundidade e rigor científico;

- benefícios para a confiança, a autoestima, a motivação, a preparação e o desenvolvimento de perspectivas diferentes sobre si e sobre os outros, com mudança de atitudes e de práticas do dia a dia;

- enriquecimento cultural e aumento do gosto pelo conhecimento;

- maior sensibilidade e capacidade para a tomada de decisão e para a justificação das práticas;

- enriquecimento do currículo do professor e progressão na carreira;

\section{Impacto na sala de aula (microimpacto)}

- oportunidade de refletir sobre a prática e melhorá-la, com alteração ou adoção de novos recursos e melhores justificativas para as práticas diárias;

- maior cuidado na preparação das aulas e na capacidade de planejar as aprendizagens dos alunos (maior motivação);

- maior capacidade para interligar assuntos e aliar os componentes científicos, técnicos e pedagógicos;

- desempenho de maior qualidade do docente (mais atentos, conscientes, rigorosos, tolerantes, sensíveis, competentes, responsáveis, organizados, confiantes, capacidade de resolver situações particulares, preparação e capacidade de organização em grupo);

\section{Impacto na escola (mesoimpacto)}

- possibilidade de mobilização dos profissionais para cargos ou funções associadas à área de especialização;

- desenvolvimento de ideias mais consolidadas, com maior atenção ao contexto da escola e da comunidade, à forma de olhar para os alunos, à mediação com os pais;

- capacidade de dar respostas mais eficazes a questões do dia a dia com maior consciência dos problemas da prática profissional do ponto de vista da escola;

- impactos na relação com os pares, na forma como trabalham e nas dinâmicas que criam;

- melhor fundamentação de ações na escola, compreensão das diretrizes pelas quais se rege e dos respectivos procedimentos;

- realização de trabalhos acadêmicos de natureza investigativa, tendo a escola como campo de ação (como contributo para a comunidade científica);

\section{Impacto nas práticas investigativas e educativas (macroimpacto)}

- estabelecimento de melhores relações, nomeadamente com os pais, com os encarregados de educação e com a própria comunidade;

- possibilidade de colaboração com o ensino superior em atividades de apoio à docência ou à investigação;

- oportunidade de gerar novos conhecimentos pelo desenvolvimento de pesquisas voltadas a questões práticas da educação;

- possibilidade de desempenho de novas funções na comunidade fora do contexto escolar e na colaboração com organismos de âmbito educativo externos à escola. 
Um grupo de 9 estudos apresenta revisões de literatura que realizam metaanálises de estudos quantitativos envolvendo os efeitos da formação do professor sobre o desempenho do aluno. Os resultados encontrados serão descritos juntamente com os demais estudos quantitativos analisados neste levantamento.

Os estudos quantitativos, em sua maioria, buscam relacionar a formação do professor com o desempenho dos alunos, utilizando análises estatísticas do tipo função de produção educacional (13 estudos), com valor agregado (4 estudos), ou outros tipos de análises estatísticas (11 estudos: correlações; regressão linear, quantílica ou multinível; análise fatorial), assumindo que os resultados dos estudantes são uma medida da qualidade da formação do professor. Em geral, não foram encontrados efeitos positivos, com exceção, em alguns casos, da formação pós-graduada nas áreas de ciências e matemática, para professores que lecionam essas disciplinas (para mais detalhes, vide Anexo B).

Além do desempenho dos alunos, aferido em testes padronizados para línguas e matemática, foram propostas outras variáveis a serem correlacionadas à formação do professor, como, por exemplo: i) taxa de evasão no ensino médio e taxa de aprovação/ reprovação (Chagas; Morandi; Barja-Fidalgo, 2017; Wayne; Youngs, 2003); ii) impacto sobre a avaliação oficial medida pelo Índice de Desenvolvimento da Educação Básica (Ideb) e pelo Exame Nacional do Ensino Médio (Enem) (Nascimento; Silva; Cavalcanti, 2013); iii) gasto por aluno, taxa aluno/professor, estrutura escolar (Hanushek, 2003).

A pós-graduação do professor, em alguns casos, foi mensurada em conjunto com outras variáveis que visavam traduzir, no conjunto, um perfil de "qualidade" profissional, como, por exemplo: i) escolaridade (o número de séries completadas pelo professor, como medida de estoque de capital humano acumulado ao longo da vida) (Barros et al., 2001); ii) inteligência e habilidade acadêmica, conhecimento específico na disciplina, conhecimento pedagógico, experiência do professor (anos de docência), certificação (inclui mestrado) (Darling-Hammond, 2000); iii) desempenho do professor em testes, características sociodemográficas (Coenen et al., 2017); iv) modalidade da pós-graduação, área temática da pós-graduação, frequência de leitura de textos e/ou livros (Lordelo; Tenório; Almeida, 2016); v) tipo de licença para docência, desempenho nos testes de licenciamento, reputação da instituição de formação (Clotfelter; Ladd; Vigdor, 2006, 2007a; Ladd; Sorensen, 2015; Goldhaber; Brewer, 2000; Buddin; Zamarro, 2009); vi) vínculo do professor com outras escolas, estabilidade do vínculo, quantidade de horas que leciona, salário do professor (Marioni; Freguglia; MenezesFilho, 2014; Marioni, 2014); vii) área do curso superior e critério de alocação dos professores às turmas (Firpo; Gonzaga; Machado, 2013). 


\section{DISCUSSÃO}

Os investimentos em políticas de formação em pós-graduação de professores da educação básica impactam o orçamento público, em geral, de duas formas: i) durante a formação, mediante programas de incentivo e de concessão de bolsas de estudo e licenças; ii) após a obtenção do título, mediante aumento no salário dos professores. A principal discussão, sob o ponto de vista de custo-benefício, portanto, é se essa formação se traduz em melhores resultados educacionais - uma relação difícil de ser avaliada.

Os resultados encontrados mostraram-se distintos, a depender da metodologia de pesquisa empregada. Os estudos que analisaram o assunto de um ponto de vista subjetivo foram capazes de acessar variáveis mais específicas, mas de mensuração menos objetiva e de abrangência mais restrita - esses estudos mostraram resultados positivos das políticas de pós-graduação de professores, quando analisados do ponto de vista do profissional, da sala de aula, das escolas e de práticas investigativas e educativas.

Por sua vez, os estudos que focaram a identificação de efeitos da titulação dos professores sobre variáveis de mensuração mais objetiva (como o desempenho dos estudantes), em sua grande maioria, não identificaram efeitos importantes, com algumas exceções de formação nas áreas de ciências e matemática, ${ }^{2}$ no caso de professores que lecionam essas disciplinas. É preciso lembrar, no entanto, que a avaliação da qualidade dos professores por meio da relação com a performance dos alunos resulta da dificuldade em avaliar esses professores por atributos mais específicos, porém subjetivos - como características lógicas, psicológicas, culturais e éticas; na verdade, não existe ainda entre os autores um consenso sobre quais são os fatores que caracterizam um professor de qualidade (quais aspectos do professor podem ser importantes e como podem ser mensurados).

Alguns autores analisaram as razões de não se ter identificado impactos evidentes da formação pós-graduada dos professores sobre o desempenho do estudante. Uma possibilidade é considerar que o efeito do professor é dependente de um contexto (de

\footnotetext{
2 Algumas discussões buscam explicar esse resultado. Darling-Hammond et al. (2000) argumentam que, em geral, o conhecimento do professor pode trazer ganhos aos seus alunos até um determinado nível de competência, acima do qual uma formação mais avançada do professor não teria efeitos adicionais; contudo, em áreas como ciências e matemática, os efeitos podem ser cumulativos, ou seja, os alunos respondem melhor a professores com formação mais avançada. Uma possibilidade é a de que essas áreas exigem raciocínios mais complexos por parte dos alunos (Justino; 2016), e professores mais bem preparados são mais capazes de identificar as necessidades de seus estudantes e mobilizar estratégias de ensino adequadas. Hill (2007) acredita que professores mais proficientes em matemática são aqueles que escolhem cursar mestrado em matemática, mas que, por serem mais proficientes, podem melhorar o desempenho dos estudantes, mesmo sem realizar essa formação. Ball (2000, apud Guimarães, 2013) acredita que, em geral, nessas áreas, exige-se mais da capacidade de racionalização dos professores, num contexto prático, e um conhecimento maior do conteúdo pode influenciar positivamente o desempenho do estudante.
} 
um currículo específico, de características específicas de alunos), e que o conteúdo de sua pós-graduação pode ser muito padronizado/generalista, incapaz de responder adequadamente a essas diferenças, ou seja, o programa de pós-graduação pode não se concentrar nas capacidades que geram resultados no desempenho do aluno (Harris; Sass, 2011). Dial (2008) concorda com esse argumento e acrescenta outra possibilidade: de que, se o título de pós-graduação for obtido somente com o objetivo de aumentar o salário, pode não necessariamente se traduzir em ganho de conhecimentos. Por outro lado, segundo o autor, o fato de o professor se aplicar em obter a titulação pode desenvolver profissionais mais comprometidos, que apresentam melhor desempenho.

Coenen et al. (2017) destacam a possibilidade de a resposta dos alunos em testes, em função do nível de formação do professor, crescer até certo limite, acima do qual níveis mais altos de educação teriam poucos efeitos. Uma abordagem semelhante faz Zuzovsky (2009), ao dizer que os professores pós-graduados podem ter dificuldade em simplificar e clarificar o entendimento avançado que desenvolvem, ao apresentá-lo aos alunos, ou seja, para o autor, talvez a experiência em lecionar seja mais importante do que o conhecimento sofisticado que o professor adquiriu.

Outro fator de consideração importante diz respeito ao método aplicado a esse tipo de estudo (a busca de impactos nos resultados de estudantes): análises causais são difíceis de serem fundamentadas no ambiente educacional, e a investigação quantitativa quase sempre envolve modelos quasi-experimentais, cujos resultados dependem de a complexidade estatística empregada ser capaz de lidar com a grande quantidade de variáveis que se inter-relacionam, o que é capaz de trazer algumas limitações quanto à consistência e à validade das medidas e dos resultados encontrados (Soares et al., 2017).

Clotfelter, Ladd e Vigdor (2007b) expõem uma visão mais crítica: se o objetivo de incluir a titulação como critério de retribuição ao professor for aumentar os resultados educacionais, talvez não seja um dinheiro bem aplicado - exceto se o objetivo for reter professores mais experientes na profissão. Nessa mesma linha, Goldhaber e Brewer (2000) argumentam que, embora essas políticas possam até gerar profissionais mais qualificados, a imposição de critérios de formação como padrão de qualidade do professor pode, em certos casos, desencorajar outros profissionais de qualidade para que permaneçam na profissão.

Kansanen (2003) apresenta o cenário de formação dos docentes da educação básica na Finlândia, destacando que todos os professores devem completar o mestrado e explica que essa política tem o objetivo de desenvolver nos docentes a capacidade de tomar decisões educacionais baseadas em juízo racional, pressupondo que eles tenham a capacidade de pensar segundo princípios de pesquisa, pela compreensão geral de métodos científicos.

Especificamente a respeito dos resultados que demonstraram melhor desempenho de professores com formação pós-graduada nas áreas de ciências e matemática (professores que lecionam essas disciplinas), Guimarães (2013) argumenta que 
professores que dominam o conteúdo dessas áreas de conhecimento podem ser mais capazes de criar oportunidades para melhorar o interesse e o aprendizado dos alunos, assim como ser mais capazes de lidar com as diferentes necessidades de aprendizado em suas turmas - em geral, exige-se mais da capacidade de racionalização dos professores nessas disciplinas, num contexto prático, e um conhecimento maior desse conteúdo pode influenciar positivamente o desempenho do estudante (Ball, 2000, apud Guimarães, 2013).

Em suma, embora os resultados, da forma como foram mensurados nos estudos quantitativos, não tenham apresentado efeitos diretos e objetivos sobre o desempenho dos estudantes, houve a percepção, por parte da maioria dos docentes que passaram por esse processo e participaram das pesquisas, de que os resultados foram positivos: do ponto de vista profissional (o desejo de aprimorar-se na profissão, compreender seu contexto e melhorar suas práticas de ensino); do ponto de vista da escola (ao desenvolver um espírito mais crítico e melhor compreensão de como agir no contexto da comunidade escolar); e do ponto de vista da produção de conhecimento (ao desenvolver seu interesse pela pesquisa, tornando-se capaz de se engajar em pesquisas práticas no dia a dia escolar).

\section{CONSIDERAÇÕES FINAIS}

Este artigo analisou a pós-graduação de professores da educação básica, com a hipótese de que o professor nessa etapa precisa ter uma formação de qualidade e em constante atualização para lidar com os desafios da educação nos dias atuais, e que a pós-graduação seria um instrumento para tal.

As discussões sobre os resultados encontrados - percepção positiva sobre a pós-graduação do ponto de vista dos professores, mas resultados inconclusivos relacionados ao desempenho dos estudantes - devem alertar os gestores de políticas educacionais no sentido de que não se pode concluir, simplesmente, que a pós-graduação não seja indicador de qualidade do professor. Esses dados podem ser indicações, por exemplo, de que tais qualificações são necessárias, mas talvez não suficientes, ou indicações de que as variáveis utilizadas nos estudos não conseguiram captar exatamente o efeito dessa formação. Muitas vezes o nível de escolaridade dos professores pode não representar a qualidade do professor em termos de desempenho dos estudantes, ou seja, a titulação, isoladamente, pode não explicar objetivamente a capacidade de agregar maior conhecimento aos alunos.

Com base no diagnóstico realizado pelo MEC em 2011 (Brasil. MEC, 2011, p. 93), como fundamentação para a elaboração do PNE, entende-se que as políticas atuais de incentivo à formação dos professores partem da premissa de que profissionais com níveis mais avançados de estudo são indivíduos que possuem uma compreensão 
melhor sobre a docência, sobre aprendizagem e sobre o desenvolvimento humano, assim como sobre as implicações pedagógicas desse conhecimento.

Embora seja importante prosseguir com as pesquisas em busca de evidências sobre os resultados das políticas de pós-graduação de professores - que explorem, talvez, outras variáveis mais sensíveis em captar eventuais efeitos da formação do professor sobre o desempenho do aluno -, os estudos qualitativos mostraram argumentos de que o processo de formação em pós-graduação se mostra importante em termos de aquisição, pelo professor, de um repertório maior de conhecimentos, de capacidade de emancipação e autonomia, de possibilidade de desenvolvimento, por parte dele, de pesquisas no ambiente escolar com foco na reflexão sobre suas práticas e na concepção de estratégias para a solução de problemas e melhoria da qualidade do ensino.

Assim, é recomendável que se desenvolva entendimento sobre as implicações e o valor agregado pela formação pós-graduada do professor, que reflita, por exemplo, a compreensão dos esforços estabelecidos pelas políticas de formação de professores como um investimento no profissional e na escola, ao se criar incentivos à formação do docente, assim como ao se cobrar resultados do desempenho desses profissionais de acordo com a formação realizada.

\section{REFERÊNCIAS}

AARONSON, D.; BARROW, L.; SANDER, W. Teachers and student achievement in the Chicago public high schools. Journal of labor Economics, Chicago, v. 25, n. 1, p. 95-135, Jan. 2007.

ALVES, E. J.; SILVA, B. D.; SILVA, R. S. Mapeamento dos estudos sobre a formação de professores no âmbito do Processo de Bolonha em Portugal. 2017. Revista Observatório, Palmas, v. 3, n. 6, p. 248-273, out./dez. 2017.

ANGELUCCI, C. B.; KALMUS, J.; PAPARELLI, R.; PATTO, M. H. S. O estado da arte da pesquisa sobre o fracasso escolar. Educação e Pesquisa, v. 30, n. 1, p. 51-72, jan./abr. 2004.

ARAÚJO, M. S. T.; AMARAL, L. H. Impactos do Mestrado Profissional em Ensino de Ciências e Matemática da Unicsul sobre a atividade docente de seus estudantes: do processo de reflexão às transformações na prática pedagógica. Revista Brasileira de Pós-Graduação, CAPES, v. 3, n. 5, p. 150-166, jun. 2006.

BALBACHEVSKY, E. A pós-graduação no Brasil: novos desafios para uma política bem-sucedida. In: BROCK. C.; SCHWARTZMAN, S. Os desafios da educação no Brasil. Rio de Janeiro: Nova Fronteira, 2005. p. 285-314. 
BARROS, R. P. D.; MENDONÇA, R.; SANTOS, D. D. D.; QUINTAES, G.

Determinantes do desempenho educacional no Brasil. Pesquisa e Planejamento Econômico, Rio de Janeiro, v. 31, n. 1, p. 1-42, abr. 2001.

BAUER, A.; SOUSA, S. Z. Indicadores para avaliação de programas educacionais: desafios metodológicos. Ensaio: Avaliação e Políticas Públicas em Educação, Rio de Janeiro, v. 23, n. 86, p. 259-284, jan./mar. 2015.

BRASIL. Lei $\mathrm{n}^{0}$ 13.005, de 25 de junho de 2014. Aprova o Plano Nacional de Educação - PNE e dá outras providências. Diário Oficial da União, Brasília, DF, 26 jun. 2014. Seção 1, p. 1.

BRASIL. Coordenação de Aperfeiçoamento de Pessoal de Nível Superior (Capes). PNPG 2011-2020. Capes: Brasília, 2010. v. 1.

BRASIL. Coordenação de Aperfeiçoamento de Pessoal de Nível Superior (Capes). Sobre pós-graduação Stricto Sensu. Brasília, 2017. Disponível em: <http://www. capes.gov.br/acessoainformacao/perguntas-frequentes/pos-graduacao-strictosensu/7443-sobre-pos-graduacao-stricto-sensu >. Acesso em: 14 jun. 2018.

BRASIL. Ministério da Educação (MEC). O PNE 2011-2020: metas e estratégias. Brasília: MEC, 2011.

BUDDIN, R.; ZAMARRO, G. Teacher qualifications and student achievement in urban elementary schools. Journal of Urban Economics, v. 66, n. 2, p. 103-115, Sept. 2009.

CASTIONI, R. Formação de pesquisadores em educação no Brasil, o papel das agências e a educação básica. Ensaio: Avaliação e Políticas Públicas em Educação, Rio de Janeiro, v. 24, n. 90, p. 199-224, jan./mar. 2016.

CHAGAS, M. A.; MORANDI, V.; BARJA-FIDALGO, C. Contribuição da pós-graduação para a educação básica: a experiência do Programa de Pós-Graduação em Biociências da Universidade do Estado do Rio de Janeiro. Revista Brasileira de Pós-Graduação, Brasília, v. 14, 2017

CLOTFELTER, C. T.; LADD, H. F.; VIGDOR, J. L. Teacher-student matching and the assessment of teacher effectiveness. Journal of human Resources, v. 41, n. 4, p. 778-820, Jan. 2006.

CLOTFELTER, C. T.; LADD, H. F.; VIGDOR, J. L. Teacher credentials and student achievement in high school: a cross-subject analysis with student fixed effects. National Center for Analysis of Longitudinal Data in Education Research, n. 13617, Mar. 2007a. 
CLOTFELTER, C. T.; LADD, H. F.; VIGDOR, J. L. How and why do teacher credentials matter for students achievements. NBER Working Paper, n. 12828, Jan. 2007b.

COENEN, J. et al. Teacher characteristics and their effects on student test scores: a systematic. Journal of Economic Surveys, v. 32, n. 3, p. 848-877, May 2017.

CRONINGER, R. G.; RICE, J. K.; RATHBUN, A.; NISHIO, M. Teacher qualifications and early learning: Effects of certification, degree, and experience on first-grade student achievement. Economics of Education Review, v. 26, n. 3, p. 312-324, Feb. 2007.

CURY, C. R. J. Quadragésimo ano do parecer CFE n. 977/65. Revista Brasileira de Educação, Rio de Janeiro, v. 30, p. 7-20, set./dez 2005.

DARLING-HAMMOND, L. Teacher quality and student achievement. Education Policy Analysis Archives, v. 8, n. 1, Jan. 2000.

DARLING-HAMMOND, L.; BERRY, B.; THORESON, A. Does teacher certification matter? evaluating the evidence. Educational evaluation and policy analysis, v. 23, n. 1, p. 57-77, Mar. 2001.

DARLING-HAMMOND, L. et al. Does teacher preparation matter? Evidence about teacher certification, Teach for America, and teacher effectiveness. Education Policy Analysis Archives, v. 13, n. 42, 2005.

DEFINIÇÃO dos cursos de pós-graduação. 1965. Disponível em: < https://www. capes.gov.br/images/stories/download/legislacao/Parecer_CESU_977_1965.pdf $>$. Acesso em: 14 jun. 2018

DIAL, J. C. The effect of teacher experience and teacher degree levels on student achievement in mathematics and communication arts. Tese (Doctor of Education). Graduate Department and Faculty of the School of Education of Baker University, Kansas (EUA), 2008.

DIXON, H.; WARD, G. The value of masters study to teachers' professional practice: contradictory discourses within the workplace. Australian Journal of Teacher Education, v. 40, n. 2, Feb. 2015

ENS, R. T. Significados da pesquisa segundo alunos e professores de um curso de pedagogia. 2006. 139 f. Tese (Doutorado em Psicologia) - Pontifícia Universidade Católica de São Paulo, São Paulo, 2006.

FARIA, A. R.; REIS, P. G. R.; PERALTA, M. H. Impactos da formação pós-graduada dos professores em escolas portuguesas. Revista Diálogo Educacional, Curitiba, v. 17, n. 54, p. 1183-1206, jul./set. 2017a. 
FARIA, A. R.; REIS, P. G. R.; PERALTA, M. H. The impact of graduate training on teachers and schools-two case studies: graduate teachers' perceptions. Ensaio: Avaliação e Políticas Públicas em Educação, Rio de Janeiro, v. 25, n. 94, p. 238-256, jan./mar. 2017b.

FIRPO, S. P.; GONZAGA, G. M.; MACHADO, D. C. A relação entre proficiência e dispersão de idade na sala de aula: a influência do nível de qualificação do professor. São Paulo: FGV/EESP 2013. (Série Texto para discussão, 338).

FONTANIVE, N. S.; KLEIN, R. O efeito da capacitação docente no desempenho dos alunos: uma contribuição para a formulação de novas políticas públicas de melhoria da qualidade da educação básica. Revista Iberoamericana de Evaluación Educativa, Madrid, v. 3, n. 3, p. 62-89, 2010.

FRANCO, A. M. P.; MENEZES FILHO, N. A. Os determinantes do aprendizado com dados de um painel de escolas do SAEB. Economia Aplicada, Ribeirão Preto, v. 21, n. 3, p. 525-548, jul./set. 2018.

FREITAS, H.C.L. PNE e formação de professores: contradições e desafios. Revista Retratos da Escola, Brasília, v. 8, n. 15, p. 427-446, jul./dez. 2014.

GIACOMAZZO, G. F. Rede de formação de professores da educação básica: análise dos princípios organizacionais em cursos de pós-graduação stricto sensu. Eccos: Revista Científica, São Paulo, n. 37, p. 93-109, maio/ago. 2015.

GOLDHABER, D. D.; BREWER, D. J. Evaluating the effect of teacher degree level on educational performance. In W. J. Fowler (Ed.). Developments in school finance. Washington, DC: National Center for Education Statistics; U.S. Department of Education, 1996. p.197-210.

GOLDHABER, D. D.; BREWER, D. J. When should we reward degrees for teachers? The Phi Delta Kappan, v. 80, n. 2, p. 134-138, Oct. 1998.

GOLDHABER, D. D.; BREWER, D. J. Does teacher certification matter? High school teacher certification status and student achievement. Educational evaluation and policy analysis, v. 22, n. 2, p. 129-145, Summer, 2000.

GOLDHABER, D. Teacher effectiveness research and the evolution of us teacher policy: the productivity for results series. George W. Bush Institute, Education Reform Initiative, Dallas, n. 5, Jan. 2015.

GUIMARÃES, R. The effect of teacher content knowledge on student achievement: a quantitative case analysis of six Brazilian states. In: REUNIÃO DA ABAVE, 7., 2013, Brasília. Anais... Rio de Janeiro: ABAVE, 2013. p. 265-278. 
HANUSHEK, E. A. The failure of input based schooling policies. The Economic Journal, v. 113, n. 485, p. F64-F98, Feb. 2003.

HARRIS, D. N.; SASS, T. R. Teacher training, teacher quality and student achievement. Journal of Public Economics, v. 95, n. 7-8, p. 798-812, Aug. 2011.

HILL, H. C. Learning in the teaching workforce. The future of children, Bethesda, v. 17, n. 1, p. 111-127, 2007.

HORN, A. S.; JANG, S. T. The impact of graduate education on teacher effectiveness: does a master's degree matter? Midwestern Higher Education Compact (MHEC), Minneapolis, Mar. 2017.

JUSTINO, David. Difícil é educá-los. Fundação Francisco Manuel dos Santos: Portugal, 2016.

KANSANEN, P. Teacher education in Finland: current models and new developments. In: MOON, B.; VLÃSCEANU, L.; BARROWS, L. C. (Eds.). Institutional approaches to teacher education within higher education in Europe. Bucharest: Unesco, 2003. p. 85-108.

KNAPP. J. L. et al. Should a Master's Degree Be Required of All Teachers? Journal of Teacher Education, AACTE-NY, v. 41, n 2, p. 27-37, 1990

LADD, H. F.; SORENSEN, L. C. Do master's degrees matter? advanced degrees, career paths, and the effectiveness of teachers. National Center for Analysis of Longitudinal Data in Education Research, Washington, n. 136, Aug. 2015.

LEITE, C. Percursos e tendências recentes da formação de professores em Portugal. Educação, Porto Alegre, v. 57, n. 3, p. 371-389, set./dez. 2005.

LORDELO, J. A. C.; TENÓRIO, R. M.; ALMEIDA, S. M. L. Desempenho do aluno e formação do professor: um exame da relação a partir dos resultados de um estudo longitudinal no ensino fundamental. Cadernos de Pesquisa: Pensamento Educacional, Curitiba, v. 11, n. 28, maio/ago. 2016.

LÜDKE, M.; CRUZ, G. B. Aproximando universidade e escola de educação básica pela pesquisa. Cadernos de Pesquisa, São Paulo, v. 35, n. 125, p. 81-109, maio/ago. 2005.

LÜDKE, M.; RODRIGUES, P. A. M.; PORTELLA, V. C. O mestrado como via de formação de professores da educação básica para a pesquisa. Revista Brasileira de Pós-Graduação, Brasília, v. 9, n. 16, p. 59-83, abr. 2012. 
MARIONI, L. S.; FREGUGLIA, R. S.; MENEZES-FILHO, N. A. Teacher quality and student achievement: evidence from Brazilian longitudinal data. 2014.

Disponível em: < https://editorialexpress.com/cgi-bin/conference/download.cgi?db_ name $=$ SBE36\&paper_id=115 $>$. Acesso em: 19 set 2018 .

MARIONI, L. S. A influência da qualidade do professor sobre a proficiência dos alunos: uma análise longitudinal. Dissertação (Mestrado em Economia Aplicada). - Programa de pós-graduação em Economia Aplicada, Faculdade de Economia, Universidade Federal de Juiz de Fora, Juiz de Fora, 2014.

MELLO, G. N. Formação inicial de professores para a educação básica: uma (re)visão radical. São Paulo em Perspectiva, São Paulo, v. 14, n. 1, p. 98-110, jan./mar. 2000.

MILHEIRO, A. R. F. P. A avaliação do impacto da formação pós-graduada nos professores e na escola: dois estudos de caso. 2017. 377f. Tese (Doutorado em Educação) - Instituto de Educação, Universidade de Lisboa, Lisboa, 2017.

MOREIRA, M. A. O mestrado (profissional) em ensino. Revista Brasileira de Pós-Graduação, Brasília, v. 1, n. 1, jul. 2004.

MOREIRA, M. A.; NARDI, R. O mestrado profissional na área de Ensino de Ciências e Matemática: alguns esclarecimentos. Revista Brasileira de Ensino de Ciência e Tecnologia, Ponta Grossa, v. 2, n. 3, set./dez. 2009.

MORICONI, G. M. Medindo a eficácia dos professores: o uso de modelos de valor agregado para estimar o efeito do professor sobre o desempenho dos alunos. 2012. 114f. Tese (Doutorado em Administração Pública e Governo) - Escola de Administração de Empresas de São Paulo, Fundação Getúlio Vargas, São Paulo, 2012.

NACARATO, A. M. O PNE e a articulação da pós-graduação com a educação básica. Zetetike, Campinas, v. 24, n. 2, p. 269-280, maio/ago. 2016.

NASCIMENTO, S. S.; SILVA, A. M. T. B.; CAVALCANTI, C. J. H. O Impacto dos mestrados profissionais na qualidade da educação em Ciências: resultados preliminares dos núcleos Minas Gerais, Rio de Janeiro e Rio Grande do Sul. 2013. Disponível em: <https://www.capes.gov.br/images/seminarios/iv-observatorioda-educacao/Educacao_Superior/O_Impacto_dos_Mestrados_Profissionais_na_ Qualidade_da_Educacao_em_Ciencias..._-_Silvania_Sousa_Nascimento.pdf $>$. Acesso em: 28 nov. 2018

NATIONAL COUNCIL ON TEACHER QUALITY (NCTQ). Restructuring teacher pay to reward excellence. Washington: NCTQ, 2010. Disponível em: <https://www.nctq. org/dmsView/Restructuring_Teacher_Pay_To_Reward_Excellence_NCTQ_Report $>$. Acesso em: 28 set. 2018. 
PORTELLA, V. C. M. Um olhar sobre o(s) sentido(s) do mestrado na formação continuada de professores do colégio Pedro II. Revista Contemporânea de Educação, Rio de Janeiro, v. 3, n. 6, p. 295-315, ago./dez. 2008.

RAMALHO, B. L.; MADEIRA, V. P. C. A pós-graduação em educação no Norte e Nordeste: desafios, avanços e perspectivas. Revista Brasileira de Educação,

Rio de Janeiro, v. 30, p. 1-13, set./dez. 2005.

RAMOS, M. Educação continuada a professores da educação básica. In: CANAL FUTURA; INSTITUTO AYRTON SENNA. Plano nacional de educação:

21 especialistas analisam as metas para 2024. São Paulo: Fundação Santillana; Moderna, 2015.

RAUSCH, R. B. Professor-pesquisador: concepções e práticas de mestres que atuam na educação básica. Revista Diálogo Educacional, Curitiba, v. 12, n. 37, p. 701-717, set./dez. 2012.

REBEQUE, P. V.; OSTERMANN, F; VISEU, S. Os mestrados profissionais em ensino de ciências e matemática no Brasil: um tema pouco explorado na literatura. Revista Brasileira de Ensino de Ciência e Tecnologia, Ponta Grossa, v. 10, n. 2, maio/ago. 2017.

RIVKIN, S. G.; HANUSHEK, E. A.; KAIN, J. F. Teachers, schools, and academic achievement. Econometrica, v. 73, n. 2, p. 417-458, Mar. 2005.

ROCKOFF, J. E. The impact of individual teachers on student achievement: evidence from panel data. American Economic Review, San Diego, v. 94, n. 2, p. 247-252, May 2004.

SANTOS, A. L. F.; AZEVEDO, J. M. L. A pós-graduação no Brasil, a pesquisa em educação e os estudos sobre a política educacional: os contornos da constituição de um campo acadêmico. Revista Brasileira de Educação, Rio de Janeiro, v. 14, n. 42, p. 534-550, set./dez. 2009.

SOARES, A. S. A formação do professor da Educação Básica entre políticas públicas e pesquisas educacionais: uma experiência no Vale do Jequitinhonha em Minas Gerais. Ensaio: Avaliação e Políticas Públicas em Educação, Rio de Janeiro, v. 22, n. 83, abr./ jun. 2014.

SOARES, T. M. et al. Modelos de valor agregado para medir a eficácia das escolas Geres. Ensaio: Avaliação e Políticas Públicas em Educação, Rio de Janeiro, v. 25, n. 94, p. 59-89, jan./mar. 2017. 
VANDERSALL, K.; VRUWINK, M.; LAVENIA, K. Research brief: master's degrees and teacher effectiveness: new evidence from state assessments. Pensylvania: Arroyo Research Services, 2012.

VERNIER, L. D. S.; BAGOLIN, I. P.; JACINTO, P. A. Fatores que influenciam o desempenho escolar no Estado do Rio Grande do Sul: uma análise com regressões quantílicas. Análise Econômica, Porto Alegre, v. 33, n. 64, set. 2015.

VIEIRA, I. F. Para uma pedagogia da experiência na formação pós-graduada de professores. Indagatio Didactica, Aveiro, Portugal, v. 1, n. 1, p. 32-75, jul. 2009.

VILLANI, A. et al. Mestrados profissionais em ensino de ciências: estrutura, especificidade, efetividade e desenvolvimento profissional docente. Investigações em Ensino de Ciências, Porto Alegre, v. 22, n. 1, p. 127-161, abr. 2017.

WAYNE, A. J.; YOUNGS, P. Teacher characteristics and student achievement gains: a review. Review of Educational Research, v. 73, n. 1, p. 89-122, Spring 2003.

WÖßMANN, L. Schooling resources, educational institutions and student performance: the international evidence. Oxford Bulletin of Economics and Statistics, v. 65, n. 2, p. 117-170, May 2003.

ZEICHNER, Kenneth M. Para além da divisão entre professor-pesquisador e pesquisador acadêmico In: GERALDI, C. M.; FIORENTINI, D.; PEREIRA, E. M. (orgs.) Cartografia do trabalho docente: professor(a)-pesquisador(a). Campinas: Mercado de Letras, 1998. p. 207-236.

ZUZOVSKY, R. Teachers' qualifications and their impact on student achievement: findings from TIMSS 2003 data for Israel. IERI Monograph Series: Issues and Methodologies in Large-Scale Assessments, v. 2, p. 37-62, 2009. 



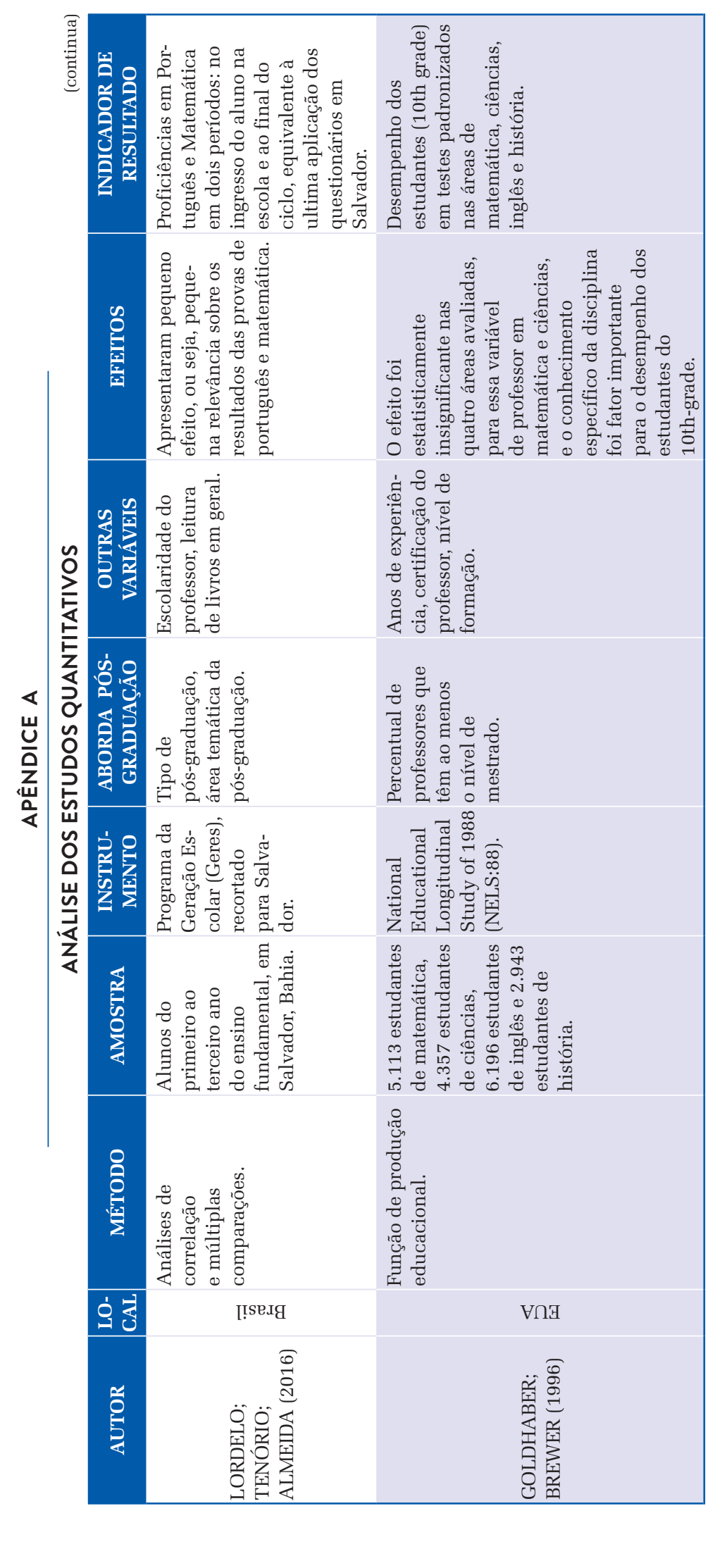




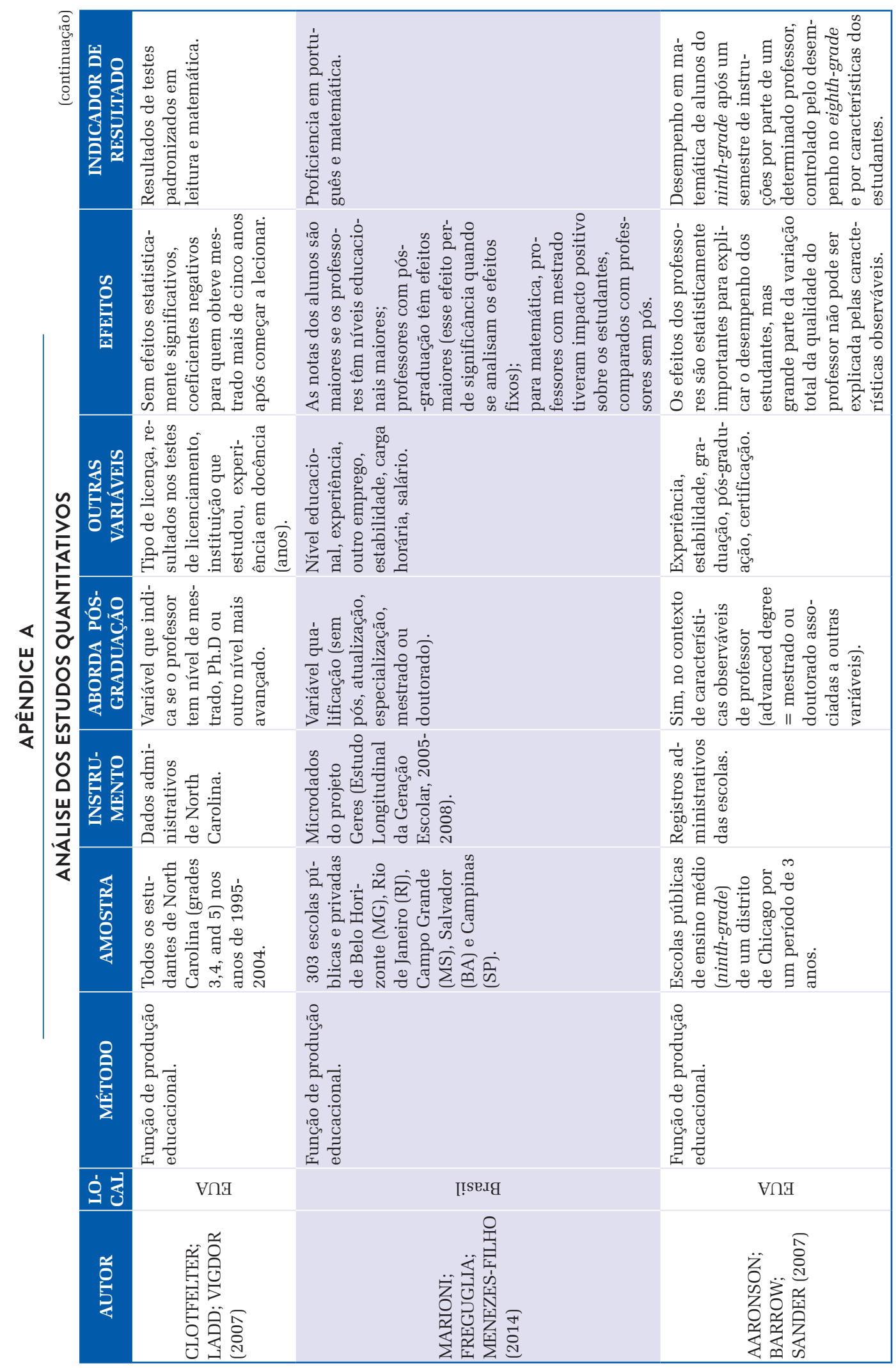




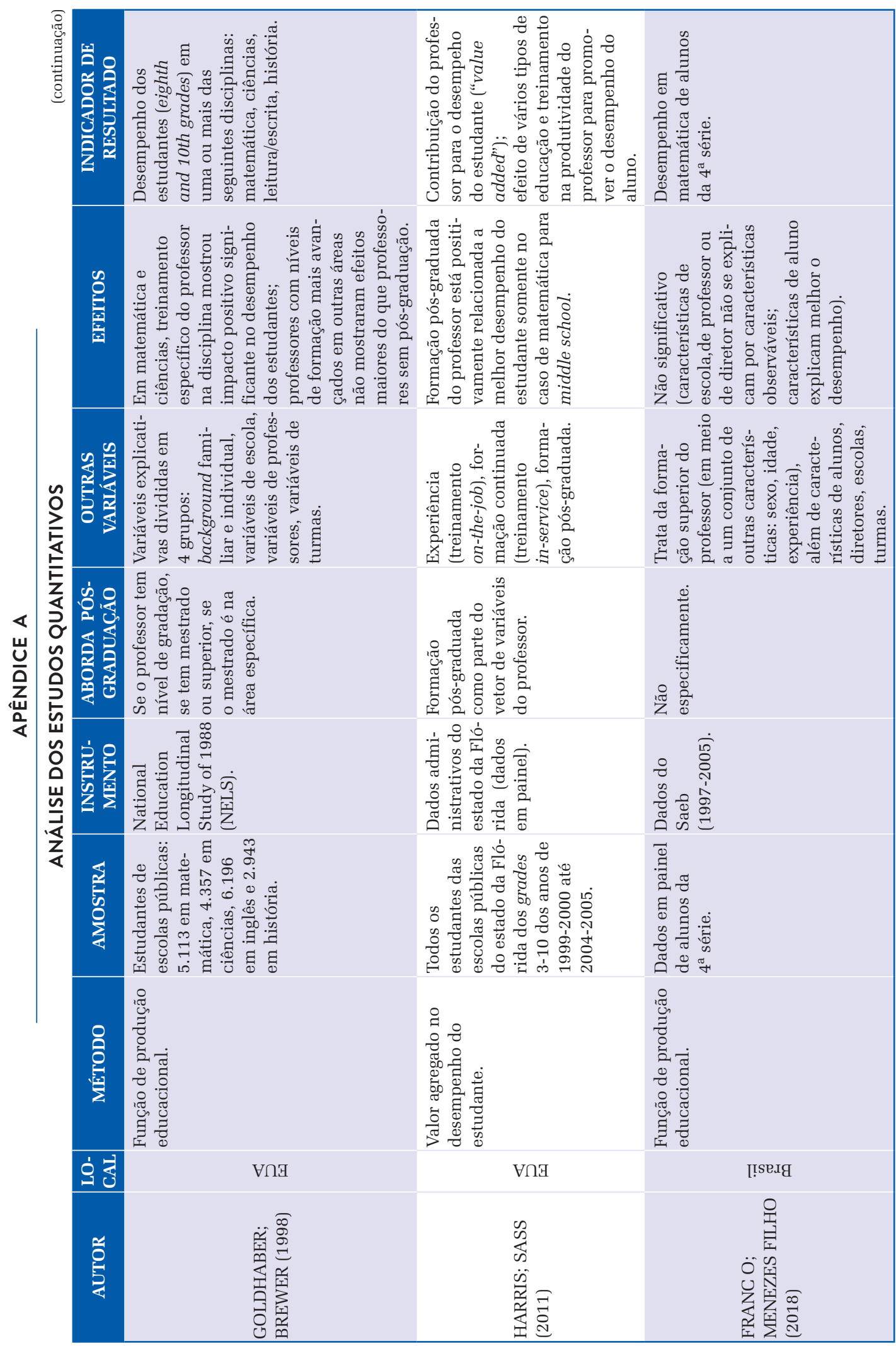




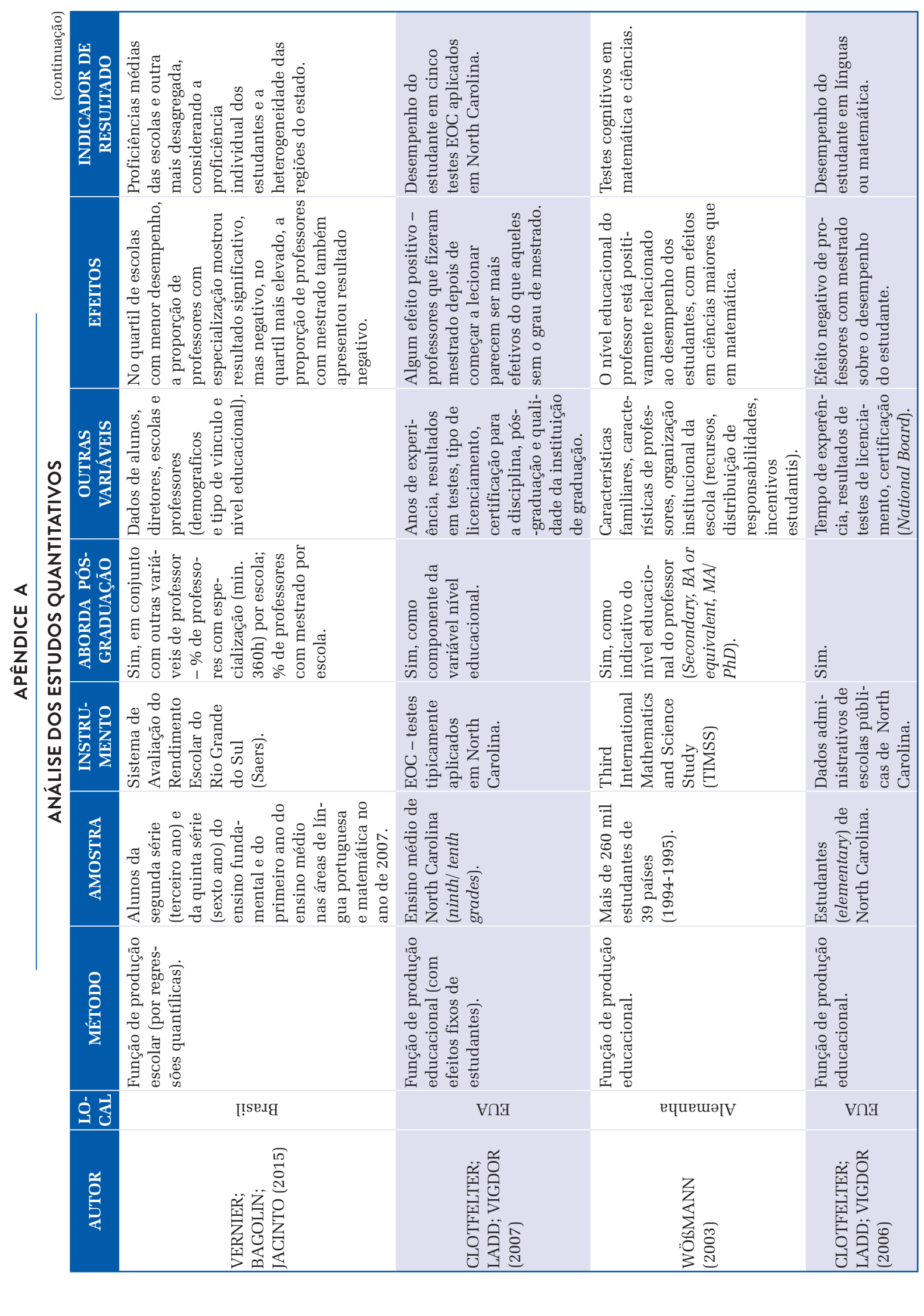




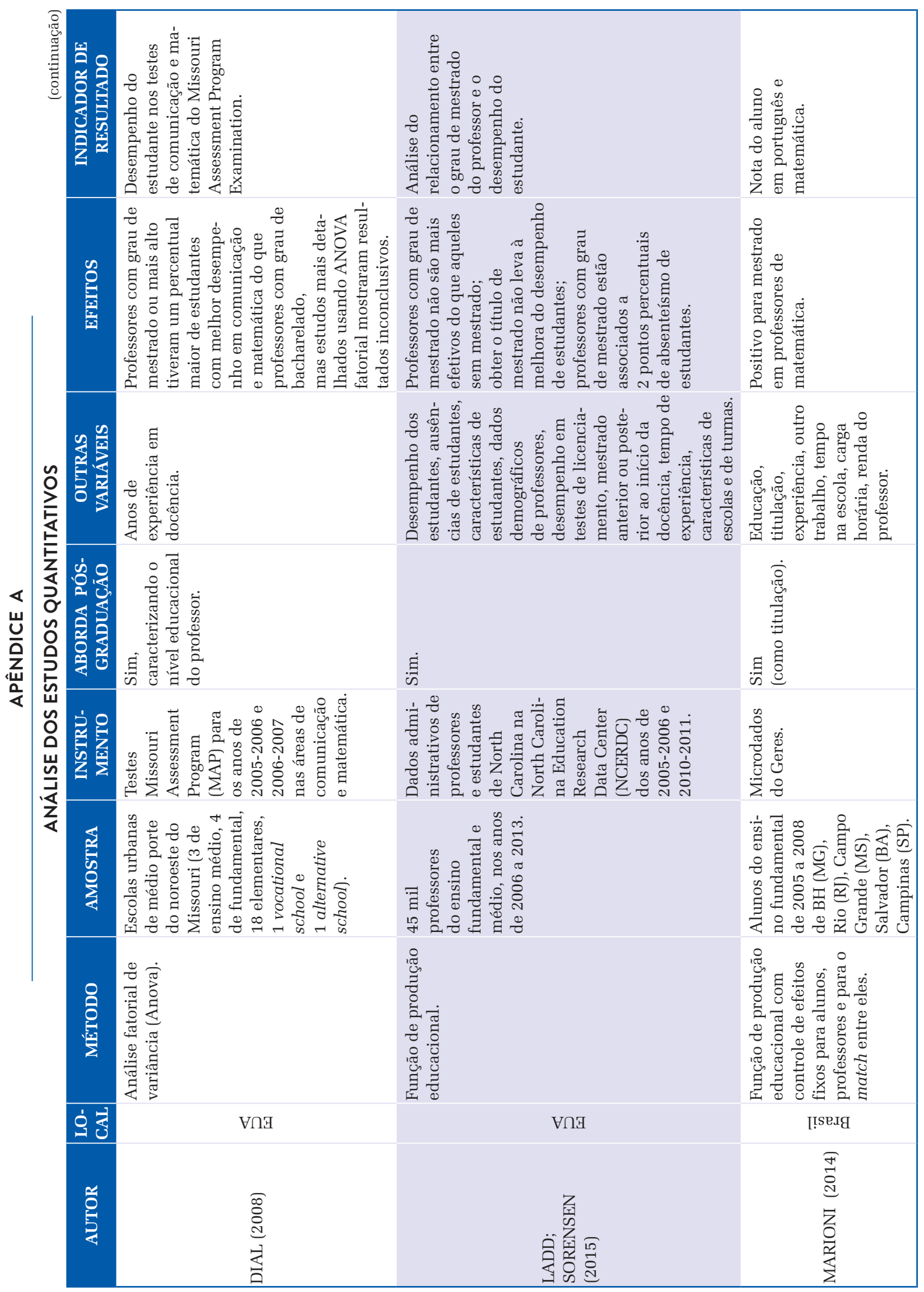




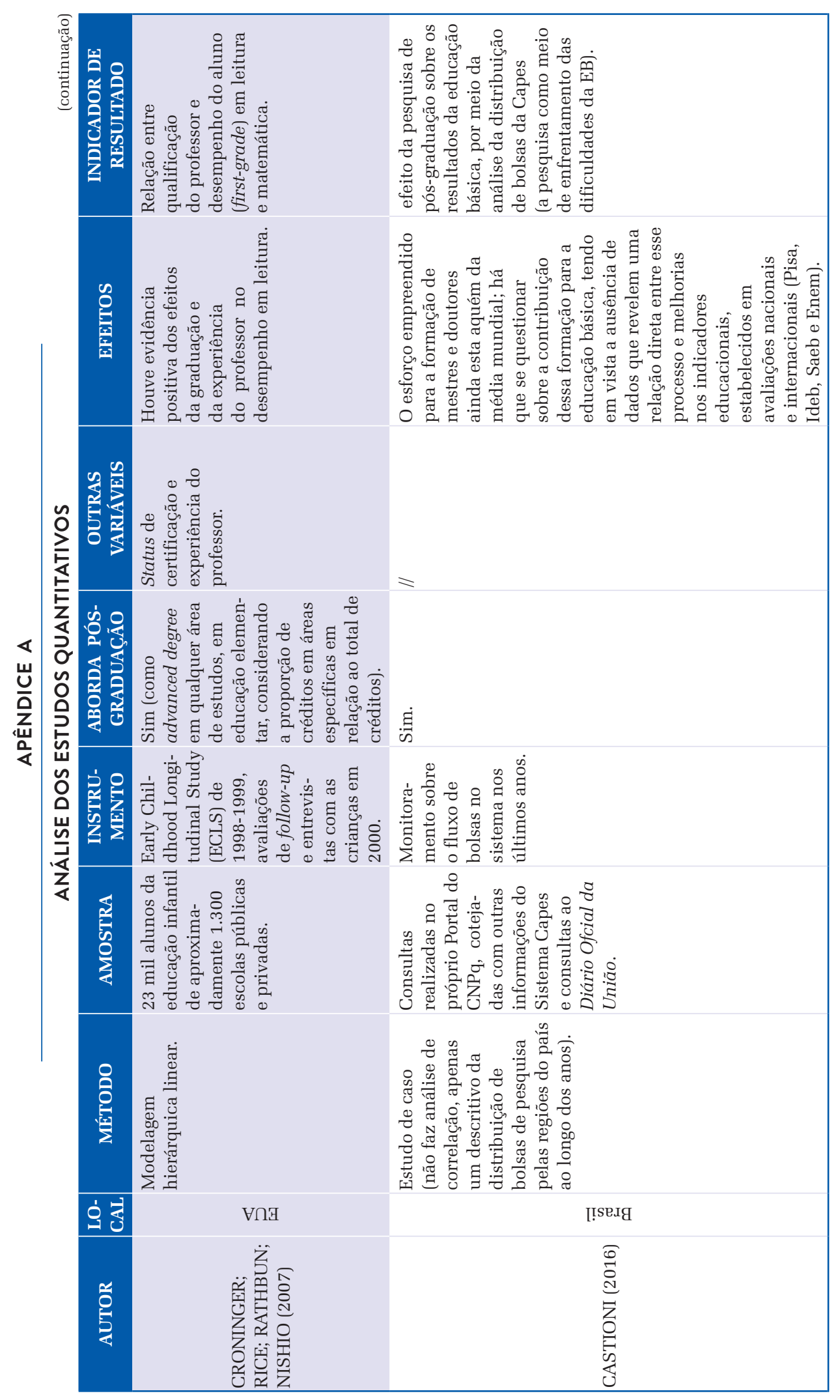




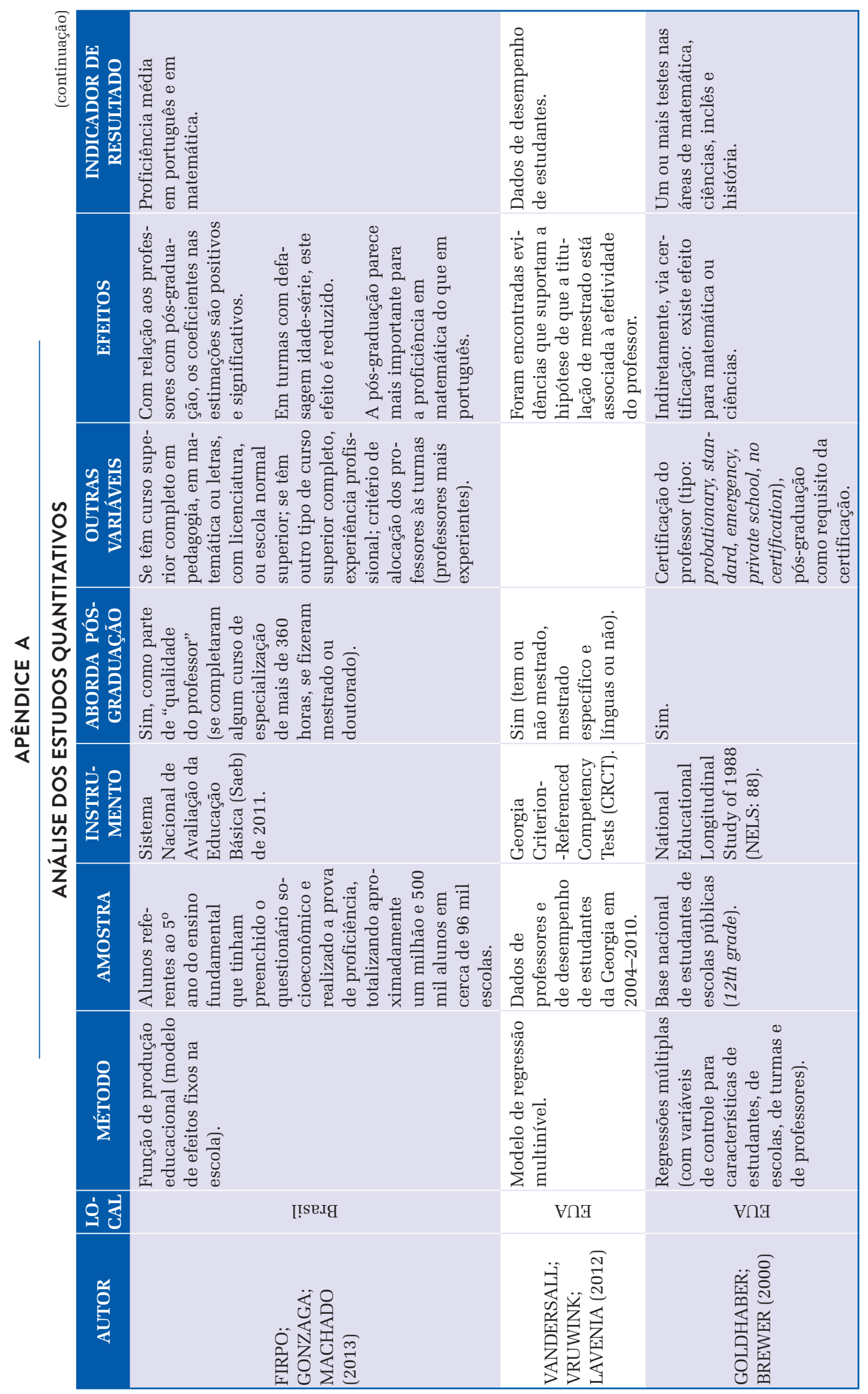




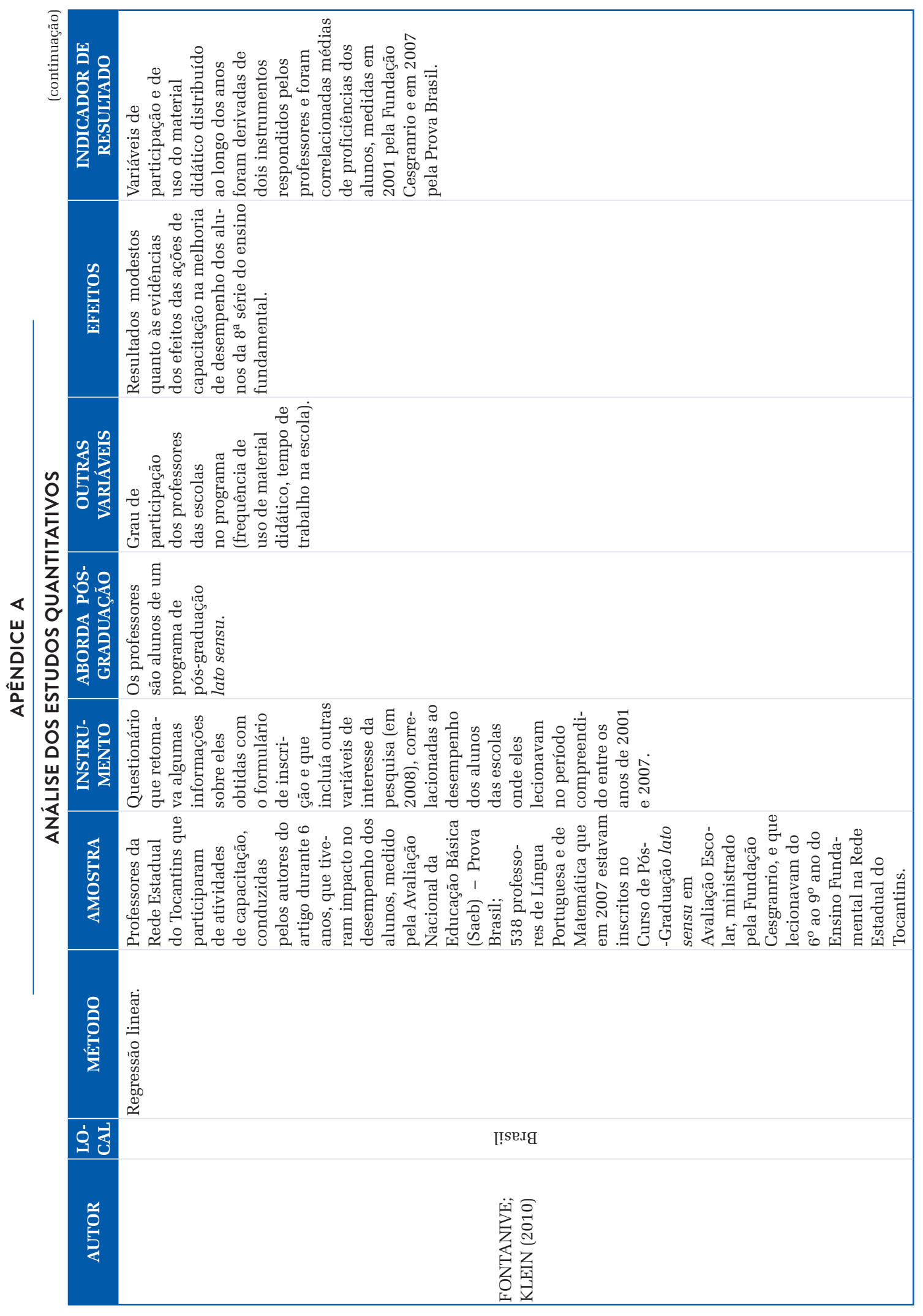




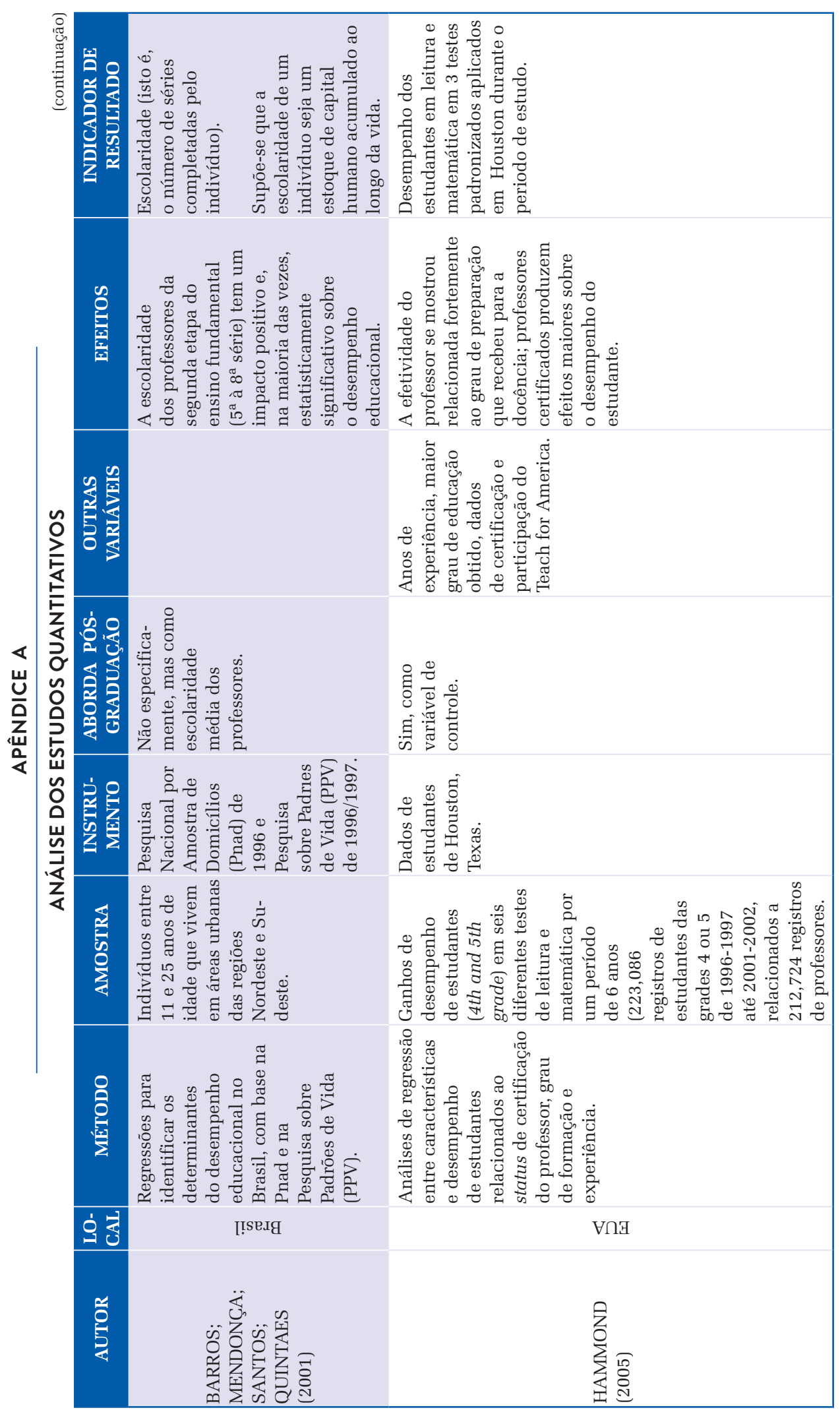




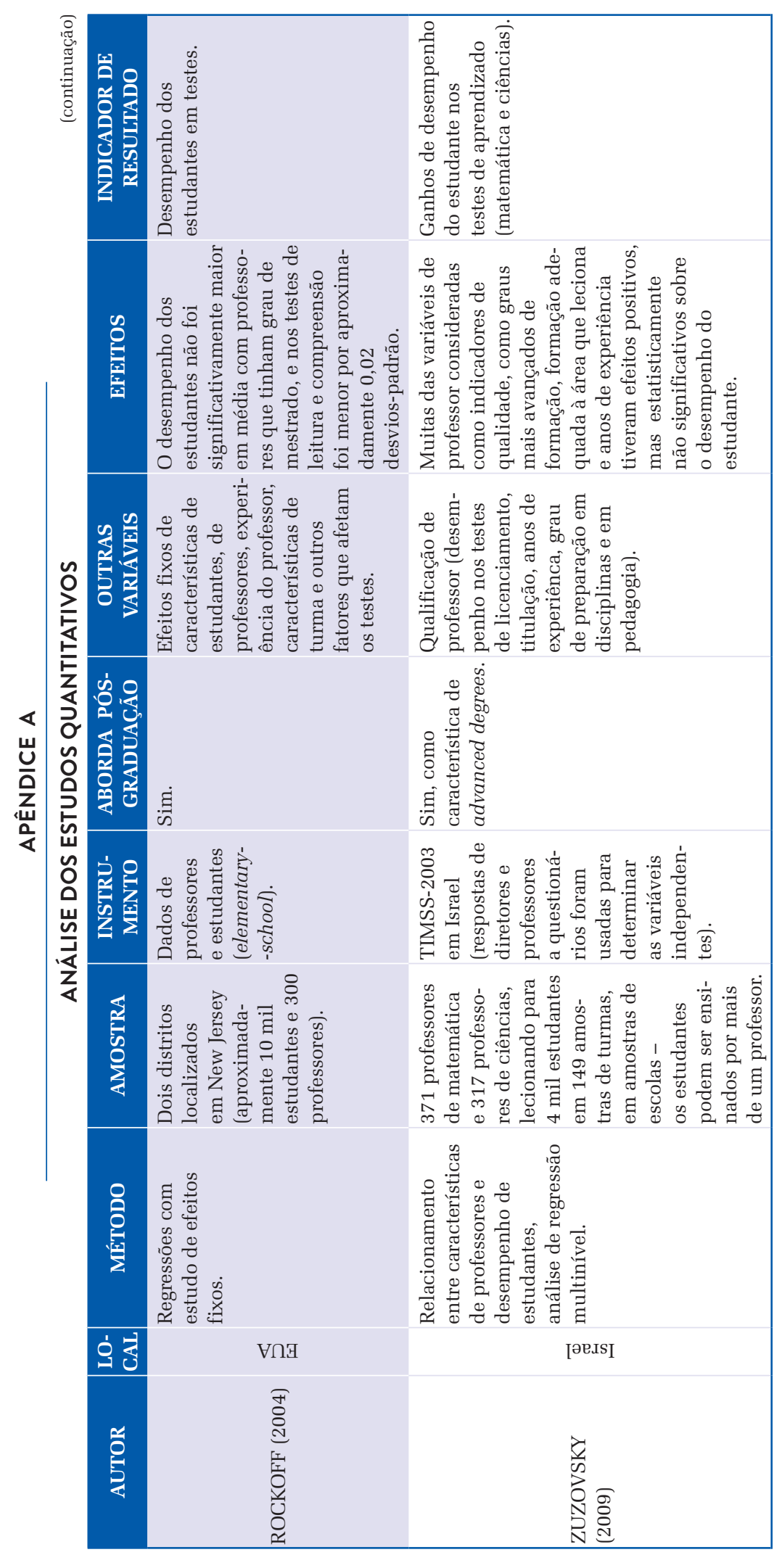




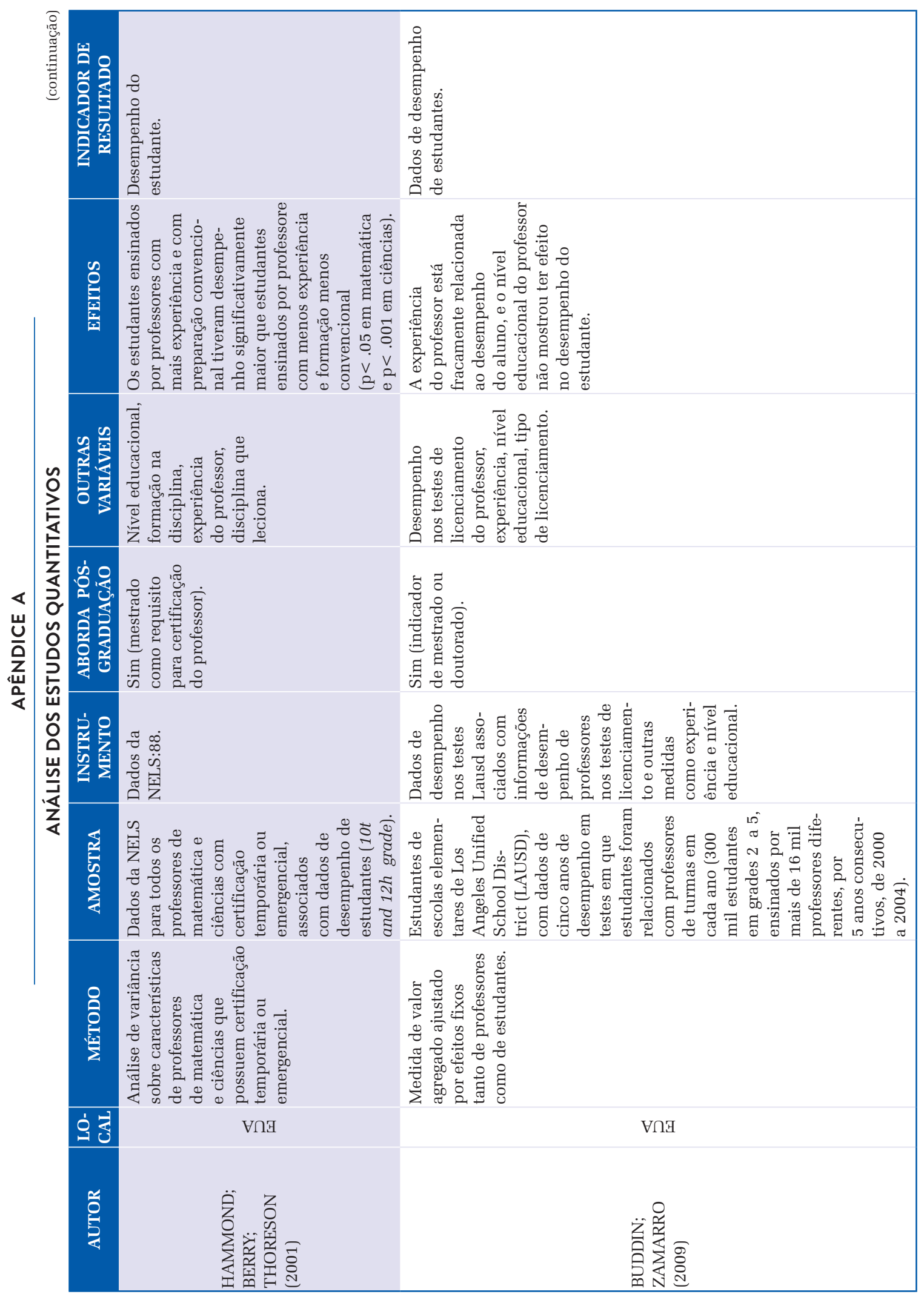




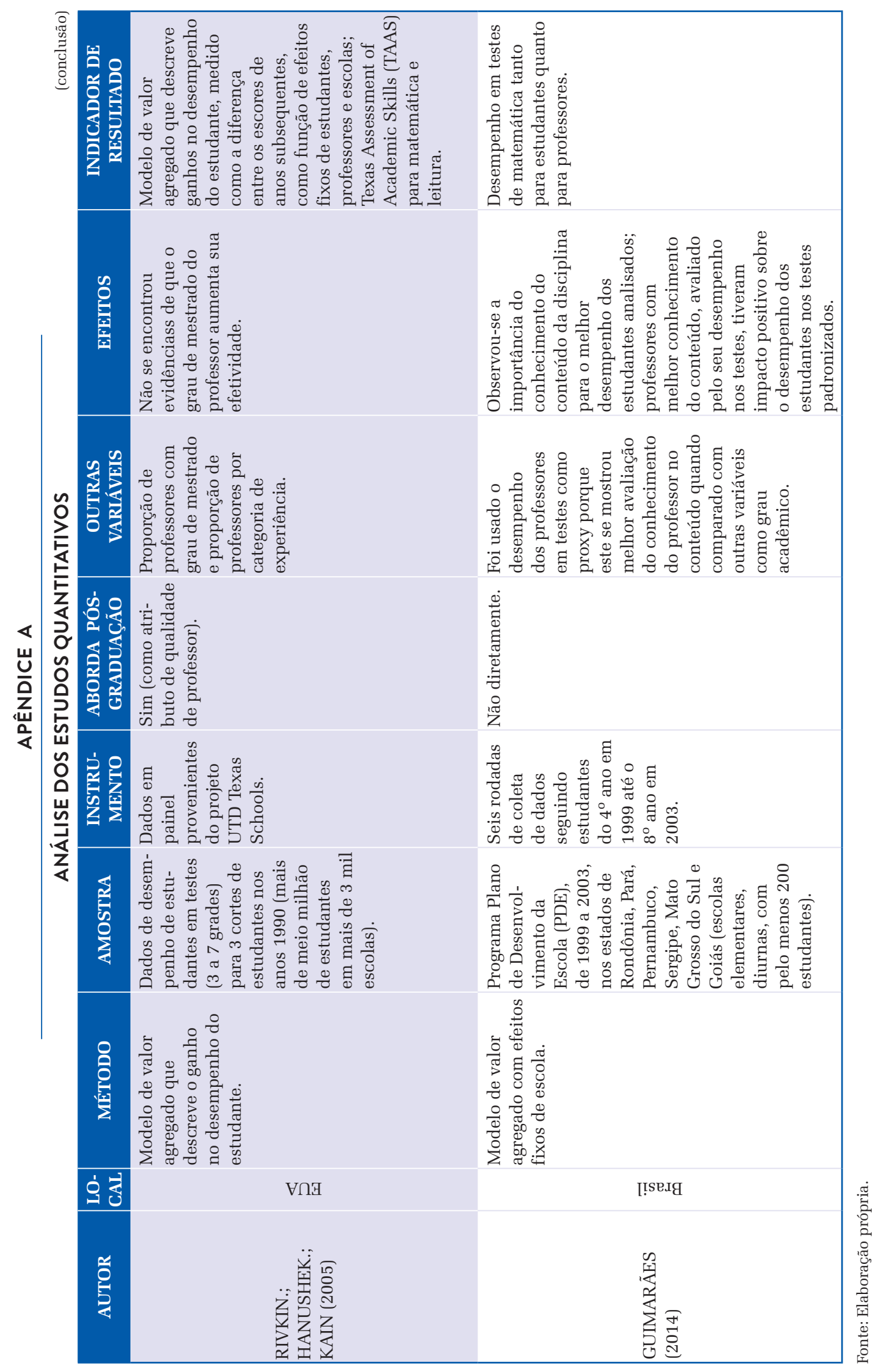

